\section{Next US tokamak in question}

\section{Washington}

WITH both sides professing to have the best interests of the US nuclear fusion research programme at heart, the fusion physics community and the Office of Energy Research at the Department of Energy (DoE) are displaying a remarkable capacity to derive opposite conclusions from the same set of facts. Physicists want to start work now on the Compact Ignition Tokamak (CIT), a \$700-million machine that, by creating a self-sustaining burn of deuterium-tritium plasma confined in a powerful magnetic field, will give them the experience they need to design an energy-producing fusion reactor. But Robert Hunter, DoE's director of energy research, believes that CIT may well fail in its goal of achieving plasma ignition and wants to put CIT to one side while some outstanding problems in plasma physics are resolved.

Enlivening the debate is an unconcealed feeling in the fusion community that Hunter wants to hold back the decades-old magnetic fusion effort in order to allow research on inertial confinement fusion, in which deuteriumtritium fuel pellets are made to implode by blasting them from all sides with laser beams, to catch up. To make legitimate this subversive plan, the physicists say, he asked DoE's Magnetic Fusion Advisory Committee (MFAC) to assemble an expert review panel to assess the chances that CIT would reach ignition, but then installed as chairman of the panel Dr Kim Molvig, an erstwhile theoretical plasma physicist from the Massachusetts Institute of Technology whom Hunter knew to be a sceptic.

To such charges Hunter responds that physicists are already guilty of overselling the present showpiece machine, Princeton's Tokamak Fusion Test Reactor (TFTR), which after seven years has still fallen short of achieving energy breakeven (a transient plasma burn which releases as much energy as was needed to create it). TFTR director Harold Furth says that this was never an official goal, although he admits that many physicists "got enthusiastic" and declared that TFTR would reach break-even. But Hunter says that in a 1981 article discussing the next generation of tokamaks, Furth gives TFTR an "energy multiplicity" of about two - twice break-even, in other words.

It was against this acrimonious background that the investigations and oversight subcommittee of the House of Representatives Committee on Science, Space and Technology last week found itself trying to make sense of plasma confinement and the validity of empirical scaling laws. After three days of hearings, in which the subcommittee heard from Furth and other fusion laboratory directors, from Molvig and other representatives of MFAC and the academic fusion community, and from Hunter himself, the entire debate on fusion policy seemed to turn on whether a value of 1.45 for a certain plasma confineexpectation or an unjustifiable extrapolation.

The physics of hot plasmas entrained in strong magnetic fields is difficult theoretically as well as experimentally. Experimenters rely on an empirical scaling law that estimates the time for which an 'Lmode' (for lowest quality) plasma of given temperature and density can be held in a given magnetic field.

With fine-tuning, machines such as TFTR and the Joint European Torus (JET) routinely attain plasma confinements better than the L-mode by a factor of two or so. In the present design for CIT, there are two construction phases: in phase I, with low field operation, an enhancement factor of 2.1 would be needed to assure plasma ignition; in phase II, a factor of 1.45 would suffice.

So, the majority of physicists at last week's hearing testified, phase I of CIT would be unlikely to achieve ignition, but in phase II a self-sustaining plasma burn would be almost a certainty.

Only at this rather advanced point in the debate does disagreement set in. In the report of MFAC Panel 22, which Molvig chaired, the statement that an enhancement factor of 1.45 is needed if CIT is to reach ignition is followed by a warning: "without a physics basis for the empirical scaling laws ... there cannot be great confidence at the present time in obtain-

\section{NETWORKS}

\section{Exploring connections}

\section{Paris}

WITH financial help from the European Science Foundation (ESF), a new network has been set up to foster European research in 'neuroimmunomodulation', a young and controversial field whose subject is the interconnections between the immune and central nervous systems. Research is aimed at exploring anecdotal evidence that, for example, depressive patients are more susceptible to physical illness. According to the proposal sent to ESF, the United States is stealing the lead "because of its ability promptly to mobilize human and material resources to explore new and promising areas of research". An ESF grant of FF590,000 (\$91,000) will be used to organize workshops and discussion meetings, once the network is launched on 15 October.

Peter Coles ment parameter was in accord with ing the performance required for ignition". This single sentence, as much as anything else, allowed Hunter to testify that there is "controversy over the scope and design of the fusion programme" and go on to propose that CIT should be delayed while the underlying physics problems were solved.

But according to Fred Ribe, chairman of MFAC itself, the cautionary statement in Panel 22's conclusions is a "molvigism", of which there were at one time many more. Ribe says that Molvig initially wanted to characterize the whole magnetic fusion programme as being "empirically based" but that a lot of "Molvig stuff" was expunged before MFAC passed the Panel 22 report on to Hunter's office. But Ribe felt that some of Molvig's statements, such as the proviso about the likelihood of achieving ignition in CIT, had to be left in, otherwise Molvig would not have accepted the panel's report.

Subcommittee chairman Robert Roe (Democrat, New Jersey) was clearly frustrated by Hunter's assertion that there was controversy over the CIT proposal, when he had previously heard 11 eminent fusion physicists testify in its favour, with only Molvig against an immediate start on the project. And Congressman David Nagle (Democrat, Iowa) established that Hunter's proposal of Molvig as chairman of Panel 22 was unusual: normally, Hunter would ask Ribe to assemble a panel. Ribe told the hearing that he had "acquiesced" in Hunter's suggestion of Molvig, in part because he was pleased by Hunter's personal interest in the fusion programme.

At the end of the three days of the hearing, committee members seemed perplexed that such a sharp disagreement could emerge when everyone, including Molvig and Hunter, agreed that something like CIT was the required next step, and when Hunter reiterated his belief that fusion ignition by the end of the century was the goal DoE should adopt. Perhaps the most clear distinction between the opposing parties was apparent when Roe asked the physicists before him for their assessment of CIT's chances.

With the exception of Molvig, all agreed that ignition was probable, and that in any case not even if the plasma did not ignite, the yield of knowledge would be invaluable. But Hunter's response is that if CIT is being sold to the Congress and to the public as an ignition machine, and fails to ignite, it will join a list of fusion devices which, like TFTR, have not quite lived up to expectations. CIT proponents worry that if the new machine does not move ahead soon, the US fusion programme will fall seriously behind its Japanese and European counterparts; Hunter's fear is that if CIT turns out be another near-miss, the setback will be worse.

David Lndley 